\title{
LAS TRAGEDIAS LATINAS DE TESIS
}

An analysis of latin praetextae as a mean of diffusion of political theories. This paper (with the same groundwork and methods proposed in "Finalidad politicodidáctica de las tragedias de Sénecan, EMERITA 44, 1976, pp. 279-301), reviews exclusively those plays in which tragic authors consciously and intentionally proposed a political thesis. This happens in the republican practextae, in the Octauia and in the work of Curiatius Maternus. All this tend to confirm the politicodidactical interpretation of Seneca's drama proposed by the author in the above mentioned work.

Redactamos estas páginas cuando acaba de aparecer nuestro artículo "Finalidad político-didáctica de las tragedias de Séneca» ${ }^{1}$, cuya tesis fundamental estriba en la consideración de que los dramas de Séneca tienen como fin esencial el servir de vehículo de transmisión de una serie de ideas politicas, pensadas para adoctrinar a Nerón sobre el recto gobierno. Después de tratar con cierto detalle las diversas bases y pruebas sobre las que hemos asentado esta idea, conclufamos afirmando que "quizá la demostración más palmaria de nuestra teoría sea la interpretación que dio a la tragedia, a finales del siglo I de C., Curiacio Materno, y la finalidad perseguida por el anónimo autor de la pretexta Octauia. Pero de ambos nos ocuparemos en otra ocasión ${ }^{2}$. El presente trabajo intentará, en la medida de lo posible, dar cumplimiento a esa promesa.

Estudiaremos, pues, aquellas tragedias latinas (o, para ser más exactos, en la mayoría de los casos fragmentos minúsculos de tragedias) en las que puede presumirse que su autor intentó incluir algún tipo de lección, generalmente de matiz político, de un modo intencionado. Por ello hemos de insistir como punto de partida en la intencionalidad de la "tesis" a la que tal o cual tragedia pretendia servir de vehículo; en segundo lugar, dejaremos a un lado aquellas obras que, si bien contienen una tesis determinada, no es ésta original en la composición por parte del dramaturgo latino. Expliquémosnos:

1 EMERITA 44, 1976, pp. 279-301.

2 Art. cit., p. 301. 
Es conocido el pasaje de la biografía de César en que Suetonio indica que, durante las exequias del dictador, se utilizaton versos de dos antiguas tragedias, el Armorum iudicium de Pacuvio y la Electra de Atilio, con una finalidad política: ad miserationem et inuidiam caedis eius accommodata ${ }^{1}$. Ahora bien, la utilización política de una obra o parte de ella, con el fin de defender o sustentar una postura o una idea, no implica forzosamente que el dramaturgo intentara un fin semejante al gestar su obra. El ejemplo de utilización de dos dramas ofrecido por Suetonio no es más que uno de los muchos que podemos encontrar en las fuentes latinas; sin embargo, en el presente trabajo nos interesan exclusivamente aquellos casos en que fue el propio tragediógrafo -y no los organizadores de los juegos, los actores o los espectadores- quien incluyó consciente o intencionadamente alguna tesis. politica en su obra.

Tampoco nos ocuparemos de las tragedias cuya intencionalidad política fue heredada por el dramaturgo latino, y que por tanto es imputable al original griego. Dado que el estado extremadamente fragmentario de la tragedia republicana no permite establecer con seguridad si los latinos heredaban sin reforma, cambiaban o evitaban las. posibles "tesis" del modelo griego inspirador, trataremos de momento sólo aquellas tragedias - las de Séneca- cuya conservación permite llegar a conclusiones fundamentales; las fragmentarias en las que conocemos directamente la intención de su autor, respondan o no a un modelo griego - así las de Curiacio Materno-; y por último, las fragmentarias que no cuentan con un precedente griego - esto es, las tragedias. praetextae-.

\section{Primeros esbozos DE tragedia politica: LAS PRAETeXtaE. REPUBLICANAS}

Sin duda la mejor definición de la tragedia praetexta es la dada por el gramático Diomedes: ...praetextae dicuntur, in quibus imperatorum negotia agebantur et publica et reges Romani uel duces inducuntur, personarum dignitate et sublimitate tragoediis similes ${ }^{2}$. De esta definición conviene destacar aquí los siguientes aspectos:

I. Interesan al argumento de la praetexta sustancialmente negotia.

1 Suet., Iul. 84 .

- Diom., Gramm. I, p. 489 Keil. Para una definición más precisa y detallada de la praetexta remitimos a nuestro trabajo "Caracterización de los géneros teatrales por los latinoss, EMMERITA 42, 1974, pp. 409-447. 
romanos que afectan de modo central a la vida política, ya sea porque se refieren a hechos de destacados personajes de la misma (imperatorum negotia), o de interés general para la nación (publica negotia).

2. Los personajes centrales que ponen en escena las pretextas han de ser, por convención dramática insoslayable, figuras relevantes en la vida pública, bien gobernantes (reges Romani), bien militares de pro (duces); ello sin descontar la gran frecuencia con que el personaje elegido se ha destacado en ambos aspectos.

3. La definición de Diomedes señala la semejanza de los personajes de las tragedias pretextas con los de las compuestas sobre originales griegos, o tragoediae propiamente dichas ${ }^{1}$. Es ésta una semejanza que no afecta exclusivamente a los personajes, sino a prácticamente todos los aspectos de las tragedias.

En consecuencia, por definición convenía a la tragedia pretexta la expresión de inquietudes sociales, sobre todo de matiz polf́tico estricto, del pueblo romano. En efecto, no es fácil conjeturar cómo un dramaturgo latino podía centrar todo un drama en torno a un personaje o un acontecimiento importante en la vida pública sin que de algún modo dejase entrever, con más o menos énfasis, con mayor o menor convicción, sus ideales socio-políticos.

La praetexta surge, como subgénero trágico de creación nacional, durante la primera generación de dramaturgos romanos, y precisamente por obra de un autor que intentó servirse del drama, en concreto de la comedia, como medio de expresión de sus inquietudes sociales y políticas, Gneo Nevio ${ }^{2}$. Es curioso observar, según se ha repetido en múltiples ocasiones ${ }^{3}$, que ya en la obra del-creador aparecen una serie

1 Cf. el articulo citado en la nota anterior, p. $4 \mathrm{I} 7$ y passim.

2 Cf. A. Pociña Peréz, "Recursos dramáticos primordiales en la comedia popular latina", $C F C 8$, 1975, pp. 264-268.

- Sobre la tragedia praetexta estimamos fundamentales, además de las páginas a ella dedicadas en los manuales de historia de la Literatura latina, los trabajos de O. Ribbeck, Die römische Tragödie der Republik, Leipzig, 1875; E. Paratore, Storia del teatro latino, Milano, 1957, passim. En cambio nos parece muy desafortunado su tratamiento en una de las obras que consideramos fundamentales sobre el drama latino, W. Beare, La escena romana, Buenos Aires, 1964, pp. 26-31. Para los textos (exceptuando la Octauia) creemos que sigue siendo segura la colección de $\mathrm{O}$. Ribbeck, en sus Tragicorum Romanorum fragmenta, Lipsiae, 1897, pp. 321-331; la edición más reciente de Lydia Pedroli, Fabularum praetextarum quae extant, Génova, 1954, tiene la ventaja de una buena introducción y una serie de notas muy útiles. En cuanto al trabajo dedicado especificamente al tema por T. Hermann, "La tragédie nationale chez les Romains", $C \& M$ 9. I948, pp. I4I-154, si bien es innegable su interés, resulta lamentable su escasa información, que lleva a buen número de inexactitudes. 
de notas que serán constantes a lo largo de todo el desarrollo histórico del nuevo subgénero. De entre estas notas queremos destacar aquí las siguientes:

I. Al menos durante la época republicana, la pretexta es cultivada, de modo muy ocasional (uno o dos títulos, y tres en un solo caso) por dramaturgos que se dedican normalmente a la tragedia de tema griego (Quinto Ennio, Marco Pacuvio, Lucio Accio) ${ }^{1}$.

2. La temática nacional de las pretextas se polarizará en dos tipos de argumento: a) tema legendario-histórico; $b$ ) tema actual.

3. En líneas generales, salvo alguna excepción, los títulos de las tragedias presentan dos formas: a) nombre de un personaje de alto interés en la vida pública, ya sea histórico, ya actual; $b$ ) nombre de un acontecimiento destacado, reflejado por medio de un nombre significativo y fácilmente interpretable (Lupus de Nevio, Sabinae de Ennio), con frecuencia el de la localidad en que tuvo lugar un hecho de armas (Clastidium de Nevio, Ambracia de Ennnio) ${ }^{2}$. Son tres aspectos que nos parecen fundamentales para los fines que aqui nos ocupan, y que, en consecuencia, trataremos de reflejar gráficamente:

\section{AUTORES, NUMERO Y TEMA DE SUS PRETEXTAS}

Praetexta
Autor $\quad \begin{gathered}\text { Praetexta } \\ \text { legendario-historica }\end{gathered}$

$\begin{array}{lll}\text { Gneo Nevio } & \begin{array}{l}\text { Lupus } \\ \text { Romulus }\end{array} & \text { Clastidium } \\ \text { Quinto Ennio } & \text { Sabinase } & \begin{array}{l}\text { Ambracia } \\ \text { Marco Pacuvio }\end{array} \\ \text { Lucio Accio } & \begin{array}{l}\text { Aeneadac siue Decius } \\ \text { Brutus }\end{array} & - \\ \text { Casio de Parma } & \text { Brutus } & \text { Praetexta de título des- } \\ \text { Lucio Cornelio Balbo } & - & \text { conocido }\end{array}$

1 Naturalmente, hay que señalar como excepciones su cultivo por Gneo Nevio, que en su aspecto de dramaturgo escribió ante todo comedias palliatae; también las dos pretextas que compusieron, al final de la República, Casio de Parma y Lucio Cornelio Balbo, dos amateurs cultos, en modo alguno dramaturgos de profesión: cf. A. Pociña Pérez, Tragediógrafos latinos menores en el periodo de la Repúblican, EC 18, 1974, pp. 83-102.

- Si bien de modo marginal, hemos tratado el problema del título de las pretextas en nuestro articulo sobre la tragedia praetexta de Lucio Cornelio Balbo", cuya publicación está prevista en $E C$. 
a) Nombre de un personaje:

$\begin{array}{ll}\text { Gneo Nevio } & \begin{array}{l}\text { Romulus } \\ \text { Marco Pacuvio }\end{array} \\ \text { Paucio Accio } & \text { (Aeneadae siue) Decius, Brutus } \\ \text { Casio de Parma } & \text { Brutus }\end{array}$

b) Nombre reflejo de un acontecimiento:

$\begin{array}{ll}\text { Gneo Nevio } & \text { Lupus, Clastidium } \\ \text { Quinto Ennio } & \text { Ambracia }\end{array}$

Las pretextas de tema histórico ofrecen el denominador común de versar sobre un hecho glorioso de los antepasados. En torno a la leyenda de la fundación de Roma transcurren las pretextas de Nevio Lupus y Romulus ${ }^{1}$, y Sabinae de Ennio. Las dos pretextas que con titulo idéntico, Brutus, escribieron un dramaturgo de profesión, Lucio Accio, y un aficionado, Casio de Parma ${ }^{2}$, tenían como tema la expulsión de Roma de los Tarquinios y la creación de la República, presentando como personaje central a Lucio Junio Bruto. Por último, la pretexta Aeneadae siue Decius de Accio cantaba la victoria romana de Sentino (año 295 a. C.), lograda merced a la heroica deuotio de Publio Decio Mus hijo, que, siguiendo el ejemplo de su padre, ofrecí su vida a los dioses para que el ejército obtuviese el triunfo ${ }^{3}$.

¿Podria pensarse que estas tragedias fueron programadas por sus autores como vehículos de difusión de algún tipo de ideas polfticas?

1 Que se trata de dos obras distintas es conjetura, muy bien fundamentada, de O. Ribbeck, Die röm. Trag., cit., p. 63 y ss. Resulta del todo inaceptable que en algunos lugares (por ejemplo, en el artículo recordado de Tage Hermann, "La tragédie nationale...., p. I43) se siga hablando de una pretexta Alimonium Romuli et Remi, título formado en base a una interpretación falsa de un pasaje de Donato que hace referencia a la pretexta Lupus (Donat., Ter. Ad. 537: falsum est quod dicitur interuenisse lupam Naeuianae fabulae alimonio Remi et Romuli, dum in theatro ageretur).

- Nosotros defendemos, siguiendo a Henry Bardon ( $\mathrm{La}$ littérature latine inconnue I, Paris, I952, p. 327), la atribución a Casio del frag. de pretexta conservado por Varrón, L. l. VI 7; VII 7. Lo mismo sostiene Antonio La Penna, "Cassio Parmense nella storia del teatro latino", SCO I9-20, 1970-71, pp. 286292, quien estudia con todo detalle la problemática referente al asunto al comienzo de su artículo (cf. también nuestro "Tragediógrafos latinos menores...» cit., pp. 9697).

- Cf. Liv. VIII 9 (sobre la deuotio de Publio Decio Mus padre) y X 28 (sobre la del hijo, que tomaba como tema la pretexta de Lucio Accio). 
Desde luego, pudiera ser; sin embargo, to que de entrada resulta indudable es su concepción patriótica ${ }^{1}$ : todas ellas aparecen enlazadas por la exaltación de un hecho glorioso de Roma. Ahora bien, esa concepción patriótica no excluye en absoluto la formulación de unos ideales que hayan coadyuvado, o puedan hacerlo en un futuro, a la grandeza de Roma. Así, prescindiendo por su gran inseguridad del pasaje que podría ser más significativo, el fragmento ribbeckiano II del Lupus de Nevio ${ }^{2}$, el valor ejemplar del héroe Decio se descubre en la mayoría de los doce fragmentos conservados de la pretexta Aeneadae siue Decius de Accio, donde se puede entrever la discusión de dos puntos de vista opuestos en los dos generales romanos que luchan en Sentino, Fabio y Decio. Maduro, lento y reflexivo, el primero propone actuar con cautela:

Quod periti sumus in uita atque usu callemus magis ':

joven, impetuoso y lanzado, Decio le señala los inconvenientes de ese modo de proceder:

Fateor: sed saepe ignauauit fortem in spe spectatio 4.

El tragediógrafo no debía ocultar su simpatía por Decio, que no en vano era el héroe de la obra. Pero quizá ello no era producto exclusivo de su atractivo ímpetu juvenil, sino en especial de su comportamiento tan "romano» al declarar su firme propósito de emular la lección patriótica recibida de su padre:

Quibus rem summam et patriam nostram quondam adauctauit pater 5 .

y, como aquél, inmolándose por la victoria romana:

1 A favor del carácter mo precisamente catártico, sino patriótico de la pretexta, se manifiesta S. Mariner, "Sentido de la tragedia en Roma", RUM I3, 1964 , pp. $486-489$.

Se trata del famoso texto:

Cedo qui rem uestram publicam tantam amisistis tam cito?

Proueniebant oratores nouei, stulti adulescentuli.

(Ribbeck, Trag., p. 322). Su transmisor, Cicerón (Cato 20) lo interpreta como pasaje de intención politica; ahora bien, el orador parece indicar que no puede tratarse de un fragmento de praetexta (quodsi legere ot audire uoletis exter $n a$, etcétera), y Lydia Pedroli lo excluye de los fragmentos de pretexta de Nevio (op. cit., p. 67).

- O. Ribbeck, Trag., fr. VI, p. 327.

- O. Ribbeck, Trag., fr. VII, p. 327.

- O. Ribbeck; Trag., fr. X, p. 328 . 
Patrio exemplo et me dicabo atque animam deuoro hostibus ${ }^{1}$.

Tal vez no sea lícito pretender encontrar aquí más que tragedia patriótica; pero, insistimos, ese patriotismo es muy susceptible de ir ligado a un ideal político, siquiera sea por lo que de selección temática hay por parte del dramaturgo: ¿por qué componer un Decius, y no un Fabius?

El problema resulta más claro cuando llegamos a las dos pretextas tituladas Brutus, sobre el creador de la república romana. La primera fue obra de Lucio Accio; si bien es cierto que el dramaturgo, nacido en 170 a. C., se encontraba en edad muy avanzada cuando lo conoció el joven Cicerón, no debe concluirse de ello que fuera ajeno a los acontecimientos políticos que marcaron el final de la república. Accio había redactado la pretexta para rendir homenaje a Décimo Junio Bruto Callaicus, el cónsul de 138 a. C., con quien, según Cicerón, le unía una estrecha amistad ${ }^{2}$; obviamente hay que ver más que una mera coincidencia entre el nombre del amigo y protector del dramaturgo, y el del héroe de la pretexta. Pero todavía hay más: la obra se repuso en Roma durante el exilio de Cicerón, y el actor Essopo, amigo del orador, conseguía que un pasaje referente al rey Servio Tulio, lo interpretase el público como alusivo a la actuación del desterrado durante la conjuración de Catilina:

Vtrum igitur haec Aesopum potius pro me aut Accium dicere oportuit, si populus Romanus liber esset, an principes ciuitatis? Nominatim sum appellatus in "Bruto":

Tullius, qui libertatem ciuibus stabiliuerat.

Miliens reuocatum est... ${ }^{3}$.

Por supuesto, Accio no pudo prever una utilización semejante de su obra en el momento de la composición; pero no es menos cierto que sería pueril suponer que los partidarios de Cicerón que motivaron la reposición del drama en el momento de su destierro hayan pensado exclusivamente en ese verso tan fácilmente manejable; el Brutus sin

O. Ribbeck, Trag., fr. XI, p. 328 .

2 Cf. Cic., Arch. 27.

8 Cic., Sest. 123. Cf. Schol. Bob. ad 1.: tragoedia praetextata Brutus inscribitur, in qua nominatus quidem Tullius uidetur, sed non idem ipse Cicero, quantum pertineat ad Accium poetam: quantum ad actorem tamen, sine dubio per qualitatem nominis utique significatio passionis eius eluxit.

7 
duda hacía hincapié en el significado político de la gran reforma llevada a cabo por el héroe. La demostración más palpable es que un tercer Bruto, en este caso Décimo Junio Bruto, el cesaricida, sintiese gran simpatía por la pretexta de Accio, sin duda no tanto por coincidencia de nombre cuanto de ideales ${ }^{1}$.

Por último, indudable es la concepción política de la pretexta Brutus de Casio de Parma ${ }^{2}$, a quien no hay que confundir con Gayo Casio Longino, el famoso tiranicida, pero que, como él, intervino también en el asesinato de Julio César. Permítasenos traer en apoyo de esta afirmación dos opiniones autorizadas: Henry Bardon, que tan gran papel ha representado en reivindicar para Casio la paternidad del drama que nos ocupa ${ }^{3}$, afirma: "Il est normal que l'un des hommes, qui allaient assassiner César, ait été séduit par Brutus, l'ennemi de Tarquin le Superbe" 4. Por su parte Antonio La Penna, a quien se debe el trabajo más pormenorizado - también el más controvertible, justo es decirlosobre la labor dramática de Casio, señala con plena razón: «È del tutto verosimile che negli anni in cui, dal 47 in poi, il potere di Cesare andava configurandosi sempre piú come una negazione delle consuetudini costituzionali e sempre piú egli veniva indicato come un "tiranno", un letterato di sentimenti repubblicani, magari per incoraggiare Bruto, scrivesse, con ispirazione acciana, una nuova tragedia sul vincitore della tirannide e fondatore della repubblica.... ${ }^{5}$.

En suma, si no en todas, al menos en las dos últimas pretextas republicanas de argumento histórico parece clara una interpretación de la tragedia de asunto nacional como susceptible de contener una lección política. Una interpretación que tal vez haya de ser considerada como razón de gran peso en la creación de este subgénero dramático, sin más que algún raro precedente griego, por parte de Gneo Nevio.

Para las pretextas de tema contemporáneo el denominador común fundamental consiste en centrar su tema en una victoria romana, que ha vivido de cerca el autor. Es lo que ocurría en dos pretextas que llevan por título el nombre de un lugar, Clastidium de Gneo Nevio y Ambracia de Quinto Ennio, que tomaban su tema de la victoria de Clastidio en 222 a. C. y de la toma de Ambracia en 189 a. C.; a ellas hay que aña-

1 Cf. Cic., Phil. X 8; Att. XVI 2; 5, etc.

- Cf. A. Pociña Pérez, "Tragediógrafos latinos menores...t, cit., pp. 96-97.

- Cf. p. 95, n. 2.

- La lit. lat. inc. I, p. 327.

s Art. cit., p. 288. 
dir el Paulus de Pacuvio, que, con bastante probabilidad ${ }^{1}$, giraba en torno a la victoria de Pidna en I68 a. C.

Hay otro punto en común entre estas pretextas: en ellas el dramaturgo ha convertido en héroe trágico a un personaje con el que está unido por estrechos lazos, normalmente un patrono o protector. Así, con respecto a la Ambracia de Ennio, por si no fuera suficiente la información ciceroniana sobre la amistad que unía al poeta con el vencedor Marco Fulvio Nobilior ${ }^{2}$, y anteriormente con su padre, al que debía la concesión de la ciudadanía romana ${ }^{3}$, el anónimo De uiris illustribuś indica taxativamente que el propósito de Ennio fue rendir homenaje a su culto protector y amigo con la obra que estamos comentando:

Quintus Fuluius Nobilior... Consul Aetolos... proeliis frequentibus uictos et in Ambraciam oppidum coactos in deditionem accepit... Quam uictoriam per se magnificam Ennius amicus eius insigni laude celebrauit ‘.

En el caso del Paulus de Pacuvio, se ha pensado en la posibilidad de que la obra fuese compuesta con vistas a su representación durante los juegos que se celebraron con motivo del triunfo de Paulo Emilio, o bien durante los juegos fúnebres en su honor ${ }^{5}$.

Nos falta la pretexta iniciadora de las de este tipo, el Clastidium de Nevio, celebrando la victoria de Marco Claudio Marcelo, y para la que también se ha pensado que estuviese destinada a la representación durante sus juegos fúnebres ${ }^{6}$. A propósito de esta obra queremos recurrir de nuevo a las tesis de una autoridad en el estudio del teatro latino, Ettore Paratore, quien advierte que Marco Claudio Marcelo era el cónsul plebeyo, el héroe de las clases bajas, y por tanto la figura popular por excelencia, cuya actuación e ideales era lógico que ensalzase Nevio, el enemigo de los nobles Metelos, el «cantore di eroi plebei» ?.

1 Se ha pensado que el Paulus del titulo pudiese corresponder a Lucio Emilio Paulo, cónsul en 216 , en cuyo caso el tema de la pretexta sería la derrota de Cannas; o bien Lucio Émilio Paulo Macedónico, cónsul en 182, de nuevo en r68, cuando tuvo lugar la batalla de Pidna que pondria fin a la tercera Guerra Macedónica. Nosotros pensamos, siguiendo esencialmente a O. Ribbeck (Die röm. Trag., cit., p. 327 ), que se trata del segundo. Cf. Lydia Pedroli, op. cit., p. r69; M. Valsa, Marcus Pacuvius poéte tragique, París, 1957, p. 50.

2 Cf. Cic., Brut. 79.

3 Cf. Cic., loc. cit.; Arch. 27; etc.

- Inc. Auct., De uir. ill. 52, 1-3.

- Cf. M. Valsa, Marcus Pacuvius..., cit., p. $5 \mathrm{I}$.

- Cf. E. Marmorale, Naeuius poeta, Firenze, 1950, p. 153, n. 10.

7 E. Paratore, Storia del teatro latino, Milano, 1957, p. 31. 
El único fragmento con sentido propio que conservamos de Clastidium se refiere indudablemente al regreso triunfal de Marco Claudio Marcelo después de la victoria:

Vita insepulta laetus in patriam redux ${ }^{1}$.

Muy poco, lamentablemente; pero compárese con un fragmento de comedia en que Nevio atacaba, si no con acritud, desde luego con malicia manifiesta, a Gneo Escipión:

Etiam qui res magnas manu saepe gessit gloriose, cuius facta uiua nunc uigent, qui apud gentes solus praestat, eum suus pater cum pallio unod ab amica abduxit?.

La tendenciosidad es obvia en este fragmento; en el Clastidium es muy verosímil que su concepción no fuese desinteresada e imparcial. De este modo, en las pretextas republicanas de tema actual, además de su innegable patriotismo, asi como una presumible muy fuerte dosis de adulación al protector, parece vislumbrarse una clara intención política en su planificación, ya fuera sentida por el dramaturgo, ya fuera una mera consecuencia de elevar al rango de héroe trágico a un personaje de la vida pública, ensalzando sus cualidades $\mathrm{y}$, de modo indudable, sus ideales.

Y llegamos así a la última, quizá también la más "original», pretexta republicana de que tenemos noticia: la que hizo representar Lucio Cornelio Balbo Minor en su ciudad natal, Cádiz, en el año 43 a. C., sobre el estrafalario tema del fracaso de una de sus misiones diplomáticas $^{3}$. Sin lugar a dudas, aquí tenemos claramente ejemplificada, siquiera sea por medio de una obra y un dramaturgo tan sui generis, la utilización política de la fabula praetexta.

En resumen, nuestra escasez de textos y de información no puede llevar a conclusiones muy amplias ni del todo libres de controversia, como hubiéramos deseado. Sin embargo, todo parece indicar que la pretexta republicana, además de su indudable patriotismo, tuvo un importante contenido político, en algunos casos al menos no desintencio-

O. Ribbeck, Trag., fr. II, p. 321.

O. Ribbeck, Com., p. 29.

- Cf. nuestro estudio en (Tragediógrafos latinos menores...s, cit., p. 97 y ss.; también en asobre la tragedia prastexta de Lucio Cornelio Balbot, próximamente en $E C$. 
nado. Por último, y como quiera que fuese, puede afirmarse con seguridad que cuando menos encerraban en sí un poderoso fermento de utilización política, que daría su fruto primero en representaciones manipuladas, después en algunas pretextas imperiales, paralelamente a la utilización política de tragedias de tema griego según vamos a observar.

\section{Tragedia politico-didactica: Seneca}

Conclúamos nuestro trabajo dedicado al estudio de la finalidad de las tragedias de Séneca ${ }^{1}$ con las siguientes conclusiones, que seguimos manteniendo cuatro años después de su redacción:

I. No se trata de dramas propiamente dichos, esto es, concebidos para ser representados, sino tan sólo para ser lefdos o recitados. Ello explica perfectamente su retoricismo: nada más natural que el encontrar un estrecho paralelismo entre las declamationes y unas tragedias pensadas para la recitación.

2. Es un teatro de amplio contenido filosófico: cosa absolutamente lógica siendo la obra de un filósofo que no pretende escribir tragedias para representarlas ante el común del pueblo.

3. Es un teatro político-didáctico: finalidad esencial, condicionada por las circunstancias en que Séneca fue primero educador y a continuación consejero político de Nerón, en fecha contemporánea a la composición de las piezas ${ }^{2}$.

Lógicamente no vamos a repetir aquí las consideraciones que nos llevaron a estas conclusiones, para las que remitimos a nuestro artículo. Sin embargo, recordadas a continuación del capítulo que precede, surgen algunas cuestiones no tomadas entonces en consideración, y sobre todo una fundamental: al concebir sus tragedias, Séneca contaba con el precedente de un subgénero trágico, la praetexta, que reunía excelentes condiciones para la expresión de ideas políticas; ¿por qué, pues, no utilizó ese subgénero, y prefirió enconmendar un fin no idéntico, pero sí muy semejante, a tragedias de tipo griego?

Hay más de una razón. Eńn efecto, no deja de ser significativo el hecho de que las aficiones poéticas, y en especial dramáticas, de Nerón vayan siempre marcadas por el más entusiasta filohelenismo. En las

1 "Finalidad político-didáctica de las tragedias de Séneca", EMmeritA 44 1976, pp. 279-301.

2 Pasaje tomado literalmente de nuestro artículo, p. 301. 
magnifficas páginas dedicadas por Henry Bardon al estudio del Nerón artista $^{1}$, descubrimos constantemente una amplia documentación sobre 1a tendencia helénica de los gustos del emperador, al que cautivaba la lengua griega ${ }^{2}$; los espectáculos griegos que tomó como modelo para instituir sus Juegos Neronianos ${ }^{3}$; los héroes de la tragedia helénica, que él mismo representaba ${ }^{4}$; 1a propia tragedia, que pretendió emular, aunque fuese en lengua latina ${ }^{5}$, etc. ¿Habría sido inteligente tratar de influir en el emperador valiéndose de la poesía trágica, y no adoptar para ello el género que prefería?

Pero hay más: los dramas de Séneca no son mera tragedia de tesis política sin más pretensiones; su finalidad esencialmente educativa, protréptica, tuvo que pesar en la elección del tema. No se trataba en absoluto de alabar el gobierno de Nerón, ni tampoco de atacarlo: ello descartaba la utilización de la pretexta de tema actual, en el caso de que a Séneca se le hubiera pasado por la cabeza la posibilidad de su empleo. $\mathrm{Y}$ en cuanto a la pretexta de tema histórico, las tendencias políticas del propio filósofo exclúan la presentación como héroe de un personaje de la República ${ }^{6}$. El fin, insistimos, era recubrir de miel un ideal y una lección política: para Nerón, la miel más adecuada era la tragedia de tipo griego.

\section{INTERNACIONALIDAD POLITICA DE LA OCTAVIA}

Todo el mundo sabe que la única muestra completa de tragedia praetexta la ofrece la en múltiples aspectos problemática Octauia ${ }^{\text {, }}$ incluida entre el Agamemnon y el Hercules Oetaeus en los mss. de la recensión A de las tragedias de Séneca, no apareciendo por el contrario en los de la mejor tradición, la del cod. Etrusco (Laur. XXXVII

1 Les Empereurs et les lettres latines d'Auguste à Hadrien, Paris, 1968, pp. 191220.

H. Bardon, op. cit., p. 196.

3 H. Bardon, op. cit., p. 199.

- H. Bardon, op. cit., p. I96 y ss.

- H. Bardon, op. cit., pp. 203-206; A. Pociña Pérez, "Agonía de la dramática latina: el teatro en tiempos de los Julio-Claudios", en Genethliakon Isidorianum, Univ. Pontificia de Salamanca, 1975, p. 489.

- Sobre los ideales politicos de Séneca, cf. "Finalidad politico-didáctica..." cit., p. 300 y ss.

- Of. Johanna Schmidt, Octauia, RE XXXIV Hb., 1937, cols. 1788-1799; L. Herrmann, Octavie. Tragédie prétexte, Paris, r924; Lydia Pedroli, op. cit., p. I7 y ss.; E. Paratore, op. cit., p. $24 \mathrm{r}$. 
13) ${ }^{1}$. E1 drama, de indudable parecido con las nueve tragedias senecanas, difiere sustancialmente de éstas por tratarse de una fabula praetexta, cuyo asunto se desarrolla en el año 62 de C., escenificando el repudio de Octavia, hija de Claudio y Mesalina, por Nerón, deseoso de casarse con Popea; para llevar a término sus deseos, el emperador relega a la infortunada heroína a la isla Pandataria, con orden de darle muerte allí.

Dos problemas principales plantea la Octania, objeto de multitud de estudios y teorías opuestas: se trata de su paternidad y de la fecha de composición. No vamos a entrar aquí sobre estos aspectos, que nos llevarían muy lejos; además, es muy probable que no consiguiéramos en absoluto convencer a quienes mantienen a ultranza las posturas menos convincentes. Sin embargo, ya que nuestra interpretación de Octania exige una previa toma de postura, señalaremos cuál es la nuestra, basada ante todo en la revisión de los múltiples trabajos que consignamos en nota, pero también en algunas consideraciones propias.

La duda sobre la paternidad senecana de la Octauia tiene ya siglos de antigïiedad y de discusión. Lydia Pedroli ${ }^{2}$ la hace remontar nada menos que a una carta de Coluccio Salutati, fechada el I5 de octubre del año I37I. La cuestión dura hasta nuestros días $^{3}$. Ahora bien, en general se cree hoy que la obra no pudo haber sido compuesta por Séneca, existiendo razones de gran peso para sostenerlo: el filósofo aparece como personaje en el drama; presencia de anacronismos que difícilmente pueden salvarse, a no ser que se parta de una postura rígida y apriorística; divergencias de lengua y métrica con respecto a las tragedias de Séneca... *

1 Cf. L. Herrmann, Sénèque, Tragédies, París, 1925, vol. I, p. VIII; Lydia Pedroli, op. cit., p. 17 y ss.

2 Op. cit., p. 24.

3 Suele encontrarse planteada, con mayor o menor detalle, en la mayoria de los estudios sobre Octauia. Un análisis muy útil de la bibliografia de los años 1922 a 1955 puede encontarse en M. Coffey, "Seneca Tragedies including pseudoSeneca Octauia and Epigrams attributed to Seneca. Report for the years 19221955", Lustrum 2, 1957, pp. II 3-I86 (Octauia en pp. I74-I84).

- Defienden la no autenticidad de Octauia por diversas razones, entre otros muchos los siguientes autores: F. Plessis, La poésie latine, Paris, 1909, p. 500; F. L. Lucas, "The Octavia", $C R$ 1921, pp. 91-93; W. Baehrens, "Die Octauia Praetexta und Senecan, $P h W$ 43, 1923, pp. 668-671; L. Herrmann, Octavie, Paris, 1924; P. J. Enk, "De Octauia Praetexta", Mnemosyne 54, 1926, pp. 390-4I5; R. Helm, "Die Praetexta Octauia", SPAW, Berlín, 1934, pp. 283-347; Gertrude Herzog-Hauser, "Reim und Stabreim in der Praetexta Octauia", Glotta 25, 1936, pp. ro9-I 16; T. Hermann, "La tragédie nationale chez les Romains", $C$ \& $M 9$, 
A pesar de ello, todavía hay recientes defensores de la atribución de Octauia al filósofo ${ }^{1}$.

Ante la dificultad enorme que supone el sostener la postura de estos últimos, se han buscado razones de más o menos peso para reivindicar en favor de otros autores la paternidad de la pretexta, llegándose a soluciones discrepantes, a menudo peregrinas: la Octauia podría pertenecer a Lucilio Junior, el destinatario de las Epistulae morales de Séneca ${ }^{2}$, a Lucano ${ }^{3}$, a Lucio Aneo Cornuto ${ }^{4}$ a Escevo Mémor ${ }^{5}$, a Ennio Floro ${ }^{6}$, a Curiacio Materno ${ }^{7}$... Tal divergencia de opiniones, poco fundamentadas en su mayoría, resulta indicio claro de la insolubilidad del problema por la vía de buscar un autor diferente de Séneca. En consecuencia, hay una marcada inclinación entre los investigadores a suponer que sea obra de un discípulo de Séneca, buen conocedor de sus tragedias y de sus escritos en prosa: desde cualquier punto de vista resulta la teoría más lógica y fundamentada, también la menos atrevida. Essta es la solución que nosotros aceptamos, con la que están de acuerdo y a la que pueden servir de nuevo apoyo las páginas que siguen.

Igualmente con respecto a la fecha en que fue compuesta la Octania se han ofrecido pareceres muy dispares, que van desde el año 65 de C., último de la vida de Séneca, en que suelen situarla los defensores de su paternidad... jhasta el siglo xvi! ${ }^{8}$. La tendencia predominante en la actualidad es considerarla poco posterior a la muerte de Nerón, y

I947, p. I49 y ss.; Lydia Pedroli, Fab. praet., cit., p. 24 y ss.; G. Runchina, sulla pretexta Octauia e le tragedie di Senecan, $R C C M$ 6, 1964, pp. 47-63; etc. (A este elenco se pueden añadir los autores que atribuyen la Octauia a diversos personajes, según indicamos a continuación.)

1 Asi, A. S. Pease, "Is the Octauia a play of Seneca?", CJ 15, 1920, pp. $3^{88-}$ 403; Id., The Octauia once mores, $C P h$ 19, 1924, pp. 80-83; S. PantzerhielmThomas, "De Octauia Praetexta», SO 24, 1945, pp. 48-87; etc. 671.

- Th. Birt, «Nochmals zur Octauia des sog. Seneca», PhW 43, r923, pp. 668-

H. Bardon, "Notes sur la littérature impériale II: Hypothèse sur l'Octavie», Latomus 3, r939, pp. 253-258.

- V. Ciaffi, "Intorno all'autore dell'Octavia», RFIC 16, 1937, pp. 246-265.

5 Cf. Lydia Pedroli, op. cit., p. 25, que califica esta atribución como una de las hipótesis "più cervellotiche".

- Cf. todo lo dicho en la nota precedente.

7 F. Ritter, Octauia praetexta. Curiatio Materno uindicatam..., Romae, 1867; T. Frank, "Curiatius Maternus and his Tragedies", $A J P h$ 58, 1937, pp. 225-229.

- Cf. E. Paratore, Storia del teatro latino, cit., p. $24 \mathrm{I}$ y ss.; Lydia Pedroli, op. cit., p. 26 y ss. 
anterior a la ascensión al gobierno del emperador Domiciano, en el año $8 \mathrm{I}^{1}$. De este modo se explica perfectamente que sea obra de un discípulo del filósofo, redactada en un período en que los hechos históricos dramatizados son recordados todavía.

Ningún escritor latino contemporáneo o inmediatamente posterior hace referencia alguna a la Octauia, de la que no se posee noticia documentada hasta el siglo xIII ${ }^{2}$. La pieza en sí es una transposición al tipo de tragedia pretexta del contenido de las de modelo griego debidas a la pluma de Séneca. Elementos comunes a ambas son su retoricismo, su contenido filosófico, perfectamente explicable si se tiene en cuenta que el desconocido autor se ha basado tanto en los dramas como en la obra en prosa del filósofo ${ }^{3}$; por último, su contenido político, estudiado con notable acierto por el prof. Montero Díaz 4 .

La Octania resulta ser, en efecto, una obra de tesis, siguiendo el modelo ofrecido por Séneca. En ella podemos encontrar una postura manifiesta correspondiente a lo que hemos llamado "reflexiones politicasi) en las tragedias de éste ${ }^{5}$; es de notar que esa postura no difiere en absoluto en sus contenidos. En efecto, sobre el tema de la fragilidad del poder se expresa por ejemplo el coro partidario de Octavia ${ }^{6}$; el gobierno tiránico es atacado aquí y allá ?, y a ello colabora sobre todo la constante insistencia en presentar a Nerón como el más cruel de los déspotas $^{8}$. La idea de las tragedias de Séneca de que el gobernante óptimo ha de ser clemente, ha de tener muy presente el ganarse el favor de los gobernados, se formula en Octauia en idéntico sentido ${ }^{\circ}$. Ni siquiera falta un claro alegato en contra de las guerras civiles, precisamente en los versos con los que el coro partidario de Octavia pone fin

1 Tampoco aquí faltan opiniones discrepantes: por ejemplo, R. Helm, «Die Praetexta Octauian, SPAW, r934, pp. 283-347, la considera escrita precisamente en época del emperador Domiciano.

2 Cf. Lydia Pedroli, op. cit., p. 18.

3 F. Préchac, Sénéque, De la clémence, Paris, I967 (1925), p. LXV y ss., ofrece un estudio comparativo de pasajes del De clementia y la Octauia, que no deja lugar a dudas sobre la intima relación y dependencia de la pretexta con respecto a la obra filosófica de Séneca.

- "Historia y politica en la pretexta Octavia", en De Caliclés a Trajano, Madrid, r948, pp. 131-157.

s Cf. "Finalidad político-didáctica...", cit., pp. 286-293.

- Octauia, v. 877 y ss.; también en el diálogo entre Séneca y Nerón, vv. 450453.

7 Asi, en las palabras de Octavia, vv. 86-93; 235 y ss.; etc.

- Cf. Octauia, 820 y ss.

- Cf. Octauia, $44^{2}$ y s.; 456 y ss.; 575 y ss. 
a la obra ${ }^{1}$; y posturas pacifistas mantienen los dos coros distintos ${ }^{2}$, así como el Séneca idealizado que el desconocido dramaturgo ha puesto en escena ${ }^{3}$.

Sin duda el mejor ejemplo de manifestación de tesis políticas divergentes es el diálogo esticomítico que enfrenta a Nerón y Séneca, defendiendo cada uno sus ideas sobre el gobierno ${ }^{4}$ :

SEN. Nihil in propinquos temere constitui decet.

NE. Iustum esse facile est cui uacat pectus metu.

SEN. Magnum timoris remedium clementia est.

NE. Extinguere hostem maxima est uirtus ducis.

SEN. Seruare ciues maior est patriae patri.

NE. Praecipere mitem conuenit pueris senem.

SEN. Regenda magis est feruida adolescentia.

NE. Aetate in hac sat esse consilii reor.

SEN. Vt facta Superi comprobent semper tua!

NE. Stulte uerebor, ipse cum faciam, deos.

Continúan todavía los razonamientos de ambos en una prolongada tirada de versos ${ }^{5}$. Es interesante notar que en este pasaje es donde, más que nunca, sigue el autor las huellas de las tragedias del filósofo. Ahora bien, dado que es indudable que el desconocido poeta se muestra siempre compenetrado con el espíritu de aquéllas, resulta claro que las ha interpretado como un teatro de finalidad esencialmente política: Séneca ha utilizado para exponer sus tesis los personajes legendarios del teatro griego; el autor de Octauia da un paso más y se vale de un tirano de la historia contemporánea. Séneca ha tenido que servirse de los coros y de ciertos personajes adecuados para exponer sus ideas; el autor anónimo emplea para ello dos coros, pero además pone en escena al mismo filósofo, fuente de sus teorías. Al lado de ello, una diferencia notable: las tragedias de Séneca añadían una finalidad «educativa", dado el carácter de ministro imperial del autor; la Octauia, por el contrario, resulta ser claramente libelística, obra de "oposición", si no real, dado que ya ha desaparecido Nerón, al menos ideológica, ejemplificadora, orientada a un futuro posible. Entre ambas hay la diferencia fundamental de las circunstancias personales del autor, y las divergencias del momento: anteriores aquéllas y posterior ésta a la

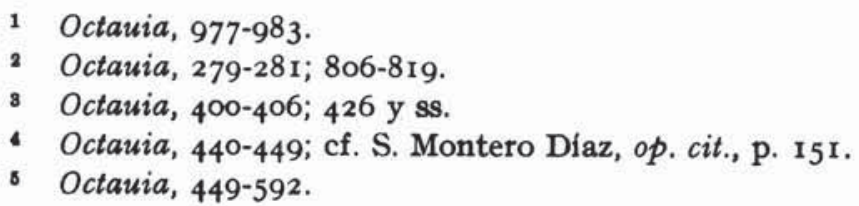


muerte de Nerón; como consecuencia de ello, el carácter de tragedias mitológicas de las obras de Séneca, frente al de pretexta de la Octauia.

De este modo, la Octauia es en nuestra opinión el colofón natural de las tragedias de Séneca: la obra que tal vez habría escrito el filósofo si hubiera sobrevivido al emperador; la demostración más palmaria de que Nerón no supo ${ }^{1}$ aprovechar la lección contenida en los dramas de su educador y ministro.

Llegados a este punto se nos plantea una cuestión enjundiosa: ¿qué relación guarda la Octauia con la pretexta republicana? Es este un aspecto que suele eludirse en los estudios sobre la obra e incluso en los dedicados a la fabula praetexta en todo su desarrollo histórico; así, una conclusión como la que pone Lydia Pedroli a su brillante estudio («Bisogna perciò concludere che se la fortuna ha voluto che di varie preteste che si scrissero in Roma questa sola si salvasse, probabilmente, se non l'ultima, una delle ultime in ordine di tempo, in essa troviamo tesaurizzati tutti gli elementi scenici, drammatici, storici che erano stati utilizzati dai predecessori» ${ }^{2}$ ), produce total insatisfacción en el lector, al que deja la impresión de haberse aludido tan sólo a un problema acaso fundamental ${ }^{3}$.

Cierto es que la escasa información de que disponemos sobre la pretexta republicana dificulta enormemente el estudio de este asunto; sin embargo, podemos llegar a alguna conclusión, al menos en los aspectos que nos ocupan en estas páginas. A semejanza de las escritas durante la República, la Octauia no se aparta en ningún momento de la normativa tradicional de este subgénero trágico, tal como la encontrábamos formulada por Diomedes, ni por lo que hace al contenido, ni a la tipología de sus personajes; de sus predecesores, el autor ha recogido la idea de una posible utilización política, que parece haber llevado a unos niveles muy superiores. Hasta aquí al menos, la Octania continúa la tradición del subgénero al que pertenece.

1 No supo, ni quiso: es curioso notar que la prolongada discusión entre Séneca y Nerón concluye con un grito de rebelión del emperador que quiere actuar sin necesidad del consejo, del visto bueno, de su preceptor y ministro:

Dosiste tandem, iam grauis nimium mihi, instare: liceat facere quod Seneca imprebat ( 588 y s.).

2 Lydia Pedroli, op. cit., p. 63.

- En términos parecidos se expresa M. Coffey en su análisis del libro de Lydia Pedroli: "Unfortunately an attempt is not made to link Octauia with what little can be known about the tradition of the Roman praetexta* (art. cit., p. 175). 
En cambio, la obra no resulta ser, al menos de entrada, un drama patriótico: ni es la alabanza de un héroe digno de admiración y emulación, ni canta un hecho brillante de la nación. Ello queda reflejado especialmente en el título, Octauia, nuevo del todo en la historia de la pretexta, que, a diferencia de la tragedia de tema griego, nunca había tomado su nombre del de una heroína; también en el tema, que por primera vez se centra en un hecho luctuoso para los romanos.

De haberse atenido por completo a las normas tradicionales, el autor tendría que titular su obra Nero, pues no es otra la figura primordial de todo el desarrollo de la acción ${ }^{1}$. Ahora bien, ello sería tanto como proclamar de entrada que la pretexta había sido completamente vencida por el modelo de la tragedia griega, dándole título, a ejemplo de un Atreus o un Thyestes, el héroe no ejemplar; por supuesto, ello iba en contra de las normas de la pretexta.

En suma, a la altura de la Octauia se produce una fusión total entre el tipo romano de tragedia griega, en la situación a que había llegado con los dramas de Séneca, y el antiguo subgénero creado por Gneo Nevio. La definición de Diomedes que recordábamos más arriba conclufa: ...personarum dignitate et sublimitate tragoediis similes ${ }^{2}$; en eI caso de Octauia, esa semejanza ha llegado al máximo, por completo en la intención por parte del dramaturgo: en este aspecto al menos sigue siendo del todo válida la afirmación bellamente formulada en el siglo xvi por un filólogo que no creía en la paternidad senecana de nuestra obra: Octauia tam similis est ceteris ut ounm ouo ${ }^{3}$.

\section{LA TRAGEDIA POR LA POLITICA: CURIACIO Materno}

Llegamos por fin a la obra dramática de Curiacio Materno, que, en tiempos de Vespasiano, fue una de las últimas figuras de interés

1 Es un hecho que se refleja incluso en la caracterización psicológica del emperador; cf. Lydia Pedroli, op. cit., p. 50 y s. ("L, figura pero che fortemente predomina nella praetexta è quella moralmente laida di Nerone, sulla quale appunto pesa tutta la responsabilità della lacrimevole fine di Ottavian).

- Diom., Gramm. I, p. 489 Keil.

3 Tomamos la cita de Lydia Pedroli, op. cit., p. 24: «... e, se più tardi Martino Antonio del Rio nella prefezione alla sua edizione del I $_{57} 6$ delle tragedie di Seneca, pur ammettendo che l'Octauia tam similis est ceteris ut ouum ouo, aut sicut similior esse non possit, escludeva pero che il filosofo Seneca potesse essere autore di tutti i dieci drammi: neque enim philosophus Seneca se ipsum in ea tragoedia loquentem introduxisset, neque tam libere Neronis uitia perstrinxisset. 
en la historia del teatro latino ${ }^{1}$. Para su tratamiento en el aspecto que aquí insteresa nos encontramos, curiosamente, en una situación del todo distinta a lo que precede. En efecto, sobre unos fragmentos de la praetexta de época republicana, sobre la obra completa de Séneca y la anónima Octauia hemos intentado descubrir el comportamiento de sus autores ante el fenómeno dramático; en el caso de Curiacio Materno, conocemos con detalle, incluso por medio de supuestas declaraciones suyas, su concepción de la tragedia como vehículo de expresión y defensa de sus ideales politicos, pero nos falta su obra, siquiera en forma fragmentaria, para poder saber de qué modo puso en práctica esa concepción.

Curiacio Materno es el más destacado interlocutor del Dialogus de oratoribus de Tácito, que tiene lugar en su propia casa, precisamente al día siguiente de haber lefdo él en público su tragedia pretexta Cato. Así, pues, entre los años 74 y 77 de C., en que se debe colocar el ficticio diálogo, tiene lugar esa lectura, cuya realidad histórica no hay razón alguna para poner en entredicho, y que iba a tener gran resonancia. Tácito lo cuenta así:

Nam postero die quam Curiatius Maternus "Catonem" recitauerat, cum offendisse potentium animos diceretur, tamquam in eo tragoediae argumento sui oblitus tantum Catonem cogitasset, eaque de re per urbem frequens sermo haberetur, uenerunt ad eum... ${ }^{2}$.

E1 autor, poniendo en escena - ficticiamente, por supuesto, ya que la obra fue recitada - una figura tan empeñada en la defensa de la República como Catón Uticense, había molestado los potentium animos, en tiempos de Vespasiano. El contenido de la obra debía de tener la fuerza suficiente para molestar, y para dar que hablar: uno de los amigos que intervienen en el Dialogus, Secundo, aconseja al dramaturgo que sea prudente, que retire de la tragedia todo aquello que pueda prestarse a una interpretación antes de proceder a su edición ${ }^{\mathbf{3}}$.

Así, pues, he aquí una tragedia pretexta concebida para la recitación y una posterior edición como libro (aspecto que deberían tener muy

1 Cf. Wissowa, Curiatius Maternus, $R E$ IV 2, I90r, cols. 1832-1834; E. Paratore, Storia del teatro latino, cit., p. 280; H. Bardon, La littérature latine inconnue II, p. 214 y ss.; etc.

2 Tac., Dial. 2.

3 Tac., Dial. 2: Tum Secundus "nihilne te" inquit, "Materne, fabulas malignorum terrent, quo minus offensas Catonis tui ames? An ideo librum istum adprehendisti, ut diligentius retractares, et sublatis si qua prauae intorpretationi materiam dederunt, emitteres Catonem non quidem meliorem, sed tamen securiorem?. 
en cuenta quienes estiman inaceptable un comportamiento semejante por parte de Séneca con respecto a sus tragedias, tan cercanas a las de Curiacio Materno en el tiempo y en la intención ${ }^{1}$ ), con una finalidad ideológica evidente: un teatro politizado, portavoz de su autor, peligroso para el mismo, pero restringido en su aspecto teatral $-\mathrm{y}$, con ello, en su trascendencia social- a obra de recitación o de lectura.

Tal es la concepción del teatro que tiene Curiacio Materno; la acaba de poner en práctica en la pretexta Cato, y piensa hacerlo a continuación en una tragedia de tipo griego, un nuevo Thyestes. ¿Por qué repetir, preguntamos nosotros, un tema que había tratado en fecha tan próxima Séneca? El Thyestes tenía la ventaja de tratarse de uno de los argumentos más adecuados para atacar al gobierno despótico, que es justamente la tarea que el dramaturgo quería encomendarle a su obra:

Tum ille «leges" inquit "quid Maternus sibi debuerit, et adnosces quae audisti. Quod si qua omisit Cato, sequenti recitatione Thyestes dicet; hanc enim tragoediam disposui iam et intra me ipse formaui. Atque ideo maturare libri huius editionem festino, ut dimissa priore cura nouae cogitationi toto pectore incumbam" ${ }^{2}$.

E1 pasaje no podría darnos una información más provechosa: la idea de su nueva tragedia, de tema griego, va a insistir en las líneas planteadas por Cato, una pretexta. Antes de centrarse en su redacción, Materno se preocupa de proceder a la edición del Cato: la tragedia se olvida así de un aspecto fundamental de la esencia del drama, la representación, y se convierte ante todo en medio de difusión de ideas en forma poética.

Gracias al reproche que hace a continuación Marco Aper a Materno de tener abandonados sus deberes de hombre distinguido e importante en la vida pública, conocemos la existencia de otra tragedia de tipo griego, Medea, y otra pretexta, Domitius ${ }^{3}$, para cuya interpretación seguimos la documentada y bien fundada de Henry Bardon: "Le Domitius de Maternus mettait en scène l'adversaire de César, L. Domitius Ahénobarbus, ou son fils, Cnaeus, partisan de Cassius et de Brutus, puis d'Antoine, avec qui il se brouilla avant de passer à Octavien" ".

1 Cf. A. Pociña Pérez, "Una vez más sobre la representación de las tragedias de Sénecan, EMmRITA 4I, 1973, pp. 297-308.

- Tac., Dial. 1 .

Tac., Dial. 3 .

- H. Bardon, Lit. lat. inc. II, p. 215. Bardon remite a este propósito a R. Schöll, Maternus, Comment. Woelfflin, Leipzig, 1891, p. 393. 
A la lectura de sus tragedias confiesa Materno deber su fama, así como un triunfo en la práctica de sus ideas políticas, como ocurrió cuando "quebrantó la funesta influencia de Vatinio», favorito de Nerón, por medio de su pretexta Nero:

Ego autem sicut in causis agendis efficere aliquid et eniti fortasse possum, ita recitatione tragoediarum et ingredi famam auspicatus sum, cum quidem in Nerone ${ }^{1}$ inprobam et studiorum quoque sacra profanantem Vatinii potentiam fregi, et hodie si quid in nobis notitiae ac nominis est, magis arbitror carminum quam orationum gloria partum ${ }^{2}$.

Hasta aquí nuestra documentación sobre los dramas de Materno. Es de destacar que en su utilización política de la tragedia el autor se haya servido por igual de las de tipo griego, tal como había hecho Séneca y con dos temas por él utilizados (Medea, Thyestes), y de la pretexta (Cato, Domitius, Nero) más o menos por el tiempo en que un autor desconocido, muy ligado a Séneca, hacía lo propio en la Octauia $^{3}$. Dicho esto, creemos que con razón afirmábamos al final de nuestra interpretación político-didáctica de las tragedias de Séneca que la dada por Curiacio Materno a sus dramas podía ser la demostración más palmaria de nuestra teoría.

ANDRÉs Pociña

Universidad de Granada

1 In Nerone mss. $C D$ : in Neronem $A B$ : imperante Nerone $L$. Müller, $H$. Haupt. Nosotros seguimos la lectura de $C D$, y la de $H$. Furneaux, ya que creemos que se trata de una pretexta titulada Nero (cf. H. Bardon, Lit. lat. inc. II p. 2 ( 5$)$.

2 Tac., Dial. II.

s Precisamente, según hemos recordado, atribuyeron la Octauia a Curiacio Materno F. Ritter (1867) y T. Frank (1937). Este último ("Curiatius Maternus and his Tragedies", $A J P h \quad 58,1937, \mathrm{pp} .225-229)$ cree que Materno atacaria el destierro de Helvidio Prisco por Vespasiano en la pretexta Cato, asi como en la Medea reflejaria el abandono de Octavia por Nerón para unirse a Popea (paralelo con Medea, Jasón y la hija de Creonte respectivamente). Sigue, pues, el método de los que identifican los personajes trágicos de Séneca con personas reales, método que nosotros rechazamos (cf. «Finalidad politico-didáctica...», cit., p. 297, nota 2); con mayor razón lo hacemos para el caso de Materno, por cuanto sobre sus tragedias no existen más noticias que las examinadas por nosotros, las cuales no dan pie para tales suposiciones. 